people. To many with outstanding reputations in research, he was a thoroughly admirable person, distinguished by his flair for using power, influence and money to get things done. To others, he was a bully and even a cheat. Among publishers, he was outstanding for his readiness personally to argue the toss about disputed royalty statements with disappointed authors. More recently, he cut the figure of a potential benefactor, dangling beneficence in front of universities (Harvard and Duke for two) and individuals - he kept Dr Robert C. Gallo on a string for several months with a scheme for an independent laboratory that came to nothing.

That Maxwell was indeed a remarkable fellow is not disputed. His energy was prodigious, as was his flair for striking advantageous deals. But he also cut corners shamelessly, as for example when he sought to sell a share in Pergamon Press to the US businessman Saul Steinberg on the basis of a balance-sheet in which unsold books and journals were counted as assets; not all his ebullience quite lived down the complaint of a British government inspector that he was not a "fit person" to run a public company. Shareholders in his companies, and the army of people they employ, will no doubt remember that complaint as they ponder on the struggles of the accountants to tell whether the debts (some $£ 2,000$ million) exceed the value of the surviving assets. It is a great pity that one so brave and energetic should so often have been so misguided.

\section{Burning tritium}

is too much being made of the most recent milestone in fusion development?

Not for the first time, research into controlled nuclear fusion (the attempt to harness thermonuclear energy such as keeps stars shining) made newspaper headlines. The result, from the Joint European Torus (JET) at Culham in Oxfordshire, England (see page 95) is genuinely important. For 30 years, fusion scientists have shied away from experiments with plasma containing both deuterium and tritium, the fuel of prospective fusion power stations, because of the irradiation of the apparatus that would follow. But now it has been tried, and the results are more than encouraging.

But is there a danger that repeated announcements of new milestones will be counter-productive, ennervating rather than enthusing those they are meant to influence? It is only two years since JET announced results also purportedly showing that the reactor was within spitting distance of 'breakeven' - the point at which fusion reactions within the hot plasma produce as much energy as needed to heat the plasma in the first place. But sleightof-hand was required on that occasion: the researchers would have been within 80 per cent of breakeven had they been using a deuterium-tritium plasma, not one of pure deuterium. Again, the actual achievement was impressive, with the product of the three key parameters in the quest for fusion power (density, temperature and energyconfinement time) being a record at that time. That result and those just announced apparently bear out the claim to pre-eminence in the field for Europe claimed by Paul Rebut, director of JET. But there is a danger of wearying the public with repeated claims of "nearly there" when the truth is, as anyone will admit, that it will be half a century before fusion reactors are used commercially.

That distant horizon is of course the problem for fusion researchers. Making fusion work means building big machines - either the conventional tokamak design in which the reacting plasma is confined magnetically or the more adventurous laser-driven 'inertial' confinement and big machines are expensive. The carrot has to be repeatedly held in front of the politicians. In that spirit, the new result could hardly have come at a better time. National representatives are meeting in Moscow this week to decide on funding for the design phase of the next multinational fusion collaboration, the International Thermonuclear Experimental Reactor (ITER). Planned to produce more than 1,000 MW of power - a thousand times the amount just produced at JET - the project could cost $\$ 5,000$ million. What better encouragement to give politicians than a new demonstration of the potential of fusion power?

To the researchers, this politicking is tiresome. Paul Rebut wearily admits that decisions on the siting of giant collaborations such as ITER (bringing together Europe, the United States, Japan and the Soviet Union) are not entirely rational. The design phase will be split between Japan, Germany and the United States. And Alan Gibson, associate director of JET, suggests that the cost of fusion research be compared with the turnover of the electricity industry; the ratio, well short of one per cent, would not look out of place in the research-and-development programme of a multinational chemical company.

Even so, researchers in the United States are looking enviously at the new JET results. Equivalent deuteriumtritium plasmas were originally intended for Princeton University's TFTR (Tokamak Fusion Test Reactor) to produce $10 \mathrm{MW}$ in 1986-87, but were turned down by the Department of Energy. Instead, Princeton will have to wait until July 1993 before it starts using tritium, and will take up the last year of that reactor's experimental programme. JET's own large-scale tritium experiments will take place in 1996, also in the last year of operations (extended six years beyond the original deadline of 1990). The present experiments are a one-time only test, timed to allow radioactivity to die away before a substantial refit of the reactor planned for next February.

Beyond that, researchers see a big blank. Princeton's Burning Plasma Experiment (BPX), intended to prepare the ground for ITER, was recently rejected by the US Department of Energy. And construction of ITER will not begin for at least four years. So, unless those working on inertial confinement fusion can pull something out of the hat, there may be a shortage of milestones in the next few years. 